\title{
Identification of Derivatives of Cobalt-binding BLM-A2 by NMR
}

\author{
Seongeon Lee, Donghyuk Shin, Sunhee Woo and Hoshik Won* \\ Department of Applied Chemistry, Hanyang University, Ansan 425-791, Korea \\ (Received Nov 7, 2012; Revised Nov 30, 2012; Accepted Dec 10, 2012)
}

\begin{abstract}
Three different derivatives were obtained in the synthesis of cobaltbinding BLM-A2 and characterized by NMR and Mass spectrometry. It was found that Component 1 is $\mathrm{Co}(\mathrm{II})\left(2 \mathrm{H}_{2} \mathrm{O}\right)(\mathrm{BLM}-\mathrm{A} 2)$, component 2 is $\mathrm{Co}(\mathrm{III})\left(\mathrm{OOH}^{-}\right)\left(\mathrm{BLM}^{-}\right.$ A2) and component 3 is $\mathrm{Co}(\mathrm{III})\left(\mathrm{H}_{2} \mathrm{O}\right)\left(\mathrm{OH}^{-}\right)(\mathrm{BLM}-\mathrm{A} 2)$, respectively. Component 2 and 3 were interestingly dominated when CoBLM-A2 complex was synthesized under basic condition. In this experiment, it was revealed newly that the brown form (component 1) was 6-coordinated structure composed with not 5 ligands but 4 ligands from BLM-A2 and with $2 \mathrm{H}_{2} \mathrm{O}$ as the axial ligands. The component 3 exhibiting a novel ligand configuration is found, and the structure of component 3 was observed to be very similar to that of component 1 in the kind of their ligands but one of the axial ligand is $\mathrm{OH}^{-}$instead of $\mathrm{H}_{2} \mathrm{O}$. These ligand configurations are different from the green form (component 2) exhibiting 6-coordinate structure composed of 5 ligands from BLM-A2 and one ligand of $\mathrm{OOH}^{-}$, being consistent with former studies.
\end{abstract}

Keywords : Bleomycin, NMR, Cobalt-binding BLM-A2, Purification

\section{INTRODUCTION}

The antitumour antibiotic bleomycins (BLMs, Figure 1) are a group of glycopeptide-derived natural products originally isolated from Streptomyces verticillus by Umezawa and co-workers. ${ }^{1}$ The clinically used BLMs is a mixture composed mainly of BLMs A2 and B2. The other minor

Department of Applied Chemistry, Hanyang University, Ansan, 425-791, Republic of Korea email : hswon@hanyang.ac.kr

Journal of the Korean Magnetic Resonance Society 2012 December; 16(2): 133-146

http://dx.doi.org/10.6564/JKMRS.2012.16.2.133 
components of BLMs are A1, A5, B4, demethyl A2 (DMBLM-A2) and bleomycinic acid. These BLMs are closely related water-soluble basic glycopeptides, which differ only in their terminal amine and has found utility against a variety of cancers, including nonHodgkins lymphomas, squamous cell carcinomas, and testicular tumors. Although this drug is widely used for cancer treatments, however, there have been many efforts to develop less toxic derivatives such as PEP because of pulmanary toxicity. $^{2-4}$
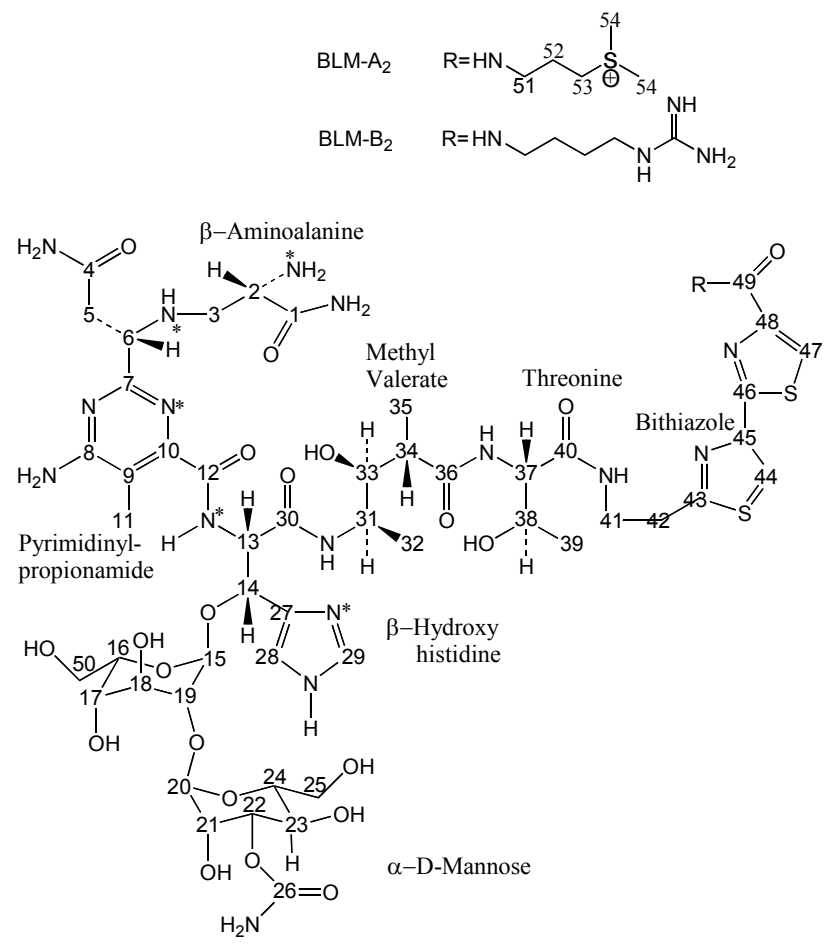

Figure 1. Molecular structure of Bleomycin. Coordinating nitrogens are denoted with asterisks $(*)$ and the primary nitrogen of the $\alpha$-amino group of the $\beta$-aminoalanine portion is supposed to be the axial ligand 
The therapeutic effectiveness of the BLMs is believed to derive from their ability to bind and oxidatively cleave cellular DNA, and possibly RNA, in the presence of certain metal ion cofactors ${ }^{4-8}$ which can support BLM-mediated DNA cleavage. Although the exact molecular arrangements of BLM ligands are not clearly known, $\mathrm{Fe}(\mathrm{II}) \mathrm{BLM}$ undergoes redox reactions with $\mathrm{O}_{2}$ that generate a active species responsible for the anticancer activity of BLM. Recent studies suggest that the active species is a ferric hydroperoxide complex. Metal [Fe(II), $\mathrm{Zn}(\mathrm{II}), \mathrm{Cu}(\mathrm{II}), \mathrm{Co}(\mathrm{II})]-\mathrm{BLM}$ complexes and their biological roles of metal ion mediation have extensively studied. ${ }^{4,8}$

Although there are many reports that BLMs bind a number of transition metal ions. And among these metals, CoBLMs have been received a great attention since metal complexes exhibit unique color on the base of the adoption of ligand and their molecular geometries. Especially the green form of Co(III)BLM-A2 has been studied very intensively for the structure and activity mechanism, which is because it is believed that the activity is due to $\mathrm{OOH}^{-}$ligand of the green form. Usually CoBLMs have been made of BLM mixture and consequently separated to each main component and purified by chromatography. They have found that there are two kinds of CoBLM-A2 complex, which are green form (Co(III)BLM-A2) and brown form (Co(II)BLM-A2). It has been thought like that as the axial ligand, $\mathrm{OOH}^{-}$is bound to $\mathrm{Co}(\mathrm{III})$ in the green from and $\mathrm{H}_{2} \mathrm{O}$ or ${ }^{-} \mathrm{OH}$ is bound to $\mathrm{Co}(\mathrm{II}$ or III) in the brown form. And as other ligands, the $\beta$-aminoalanine (as another axial ligand), pyrimidine and hystidine region is bound to metal. ${ }^{4,10,14}$ Many kinds of studies have been performed with various spectroscopic and chemical techniques ${ }^{4,9}$ for determination of CoBLMs structure and elucidating antitumour activity that is related to their structures. 
But there are remained elusive things so far what the precise structures of CoBLMs are, what the action mechanism is and how many kinds of conformational structures are made. So we tried to research in different way how many kinds of conformational structures are made and what those are. First, we separated pure BLM-A2 from the mixture and then made CoBLM-A2 complex from purely separated BLM-A2. In this experiment we have found three kinds of compound of Co(III)BLM-A2 and elucidated the structures with ESI-mass.

\section{EXPERIMENTAL METHODS}

Materials and Reagents BLEOCIN $^{\circledR}$ (potency; 15mg, a mixture of BLM A2 62\%, BLM B2 32\%, DMBLM-A2 4.7\% and others on HPLC chromatogram) was purchased from Nippon Kayaku, Tokyo, Japan and used to separate Bleomycin A2, the main component of BLMs. HPLC-grade methanol and acetonitrile was obtained from Fisher (U.S.A.). Ultra-pure water was obtained from a purification line consisting of RO4 and Milli-Q systems (Millipore, Bedford, MA, U.S.A.) mounted in series. Mixtures of methanol / water and mobile phase were degassed by filtration through a membrane filter (0.45 um x $47 \mathrm{~mm}$, msi Micron Separations Inc., U.S.A.) before use and on using with hellium sparging or vacuum degaser. First grade acetic acid and ammonium acetate were obtained from Duksan Pharm.(Korea). Cobalt(II) chloride 97\%, was purchased from Aldrich(U.S.A.).

Purification of BLM-A2 BLM-A2, the major component, was purified from 6 ampules of BLEOCIN $^{\circledR}$. HPLC analysis and purification was performed using a Waters Module 1 Plus equipped with Shiseido Capcell Pak column $\left(\mathrm{C} 18,4.6 \times 150 \mathrm{~mm}, 5 \mathrm{um}\right.$, Japan). The mobile phase ${ }^{11,12}$ was 
$20 \mathrm{mM}$ ammonium acetate in $0.1 \%$ acetic acid, which was filtered and degassed on using with helium sparging. The mobile phase was delivered at $1.5 \mathrm{~mL} / \mathrm{min}$. to Shiseido Capcell Pak column (C18, 4.6 $\times 150 \mathrm{~mm}, 5 \mathrm{um}$, Japan) with the following program: mobile phase only for $5 \mathrm{~min}$., followed by a linear gradient to $70 \%$ of methanol in $8 \mathrm{~min}$. and isocratic ( $70 \%$ methanol in the mobile phase) for 4 min. The eluate was passed through a variable-wave length UV detector set at $290 \mathrm{~nm}$ and subsequently collected in sample tubes by fraction collector, EYELA DC 12000. The chromatograms were recorded with a Waters 746 data module. The collected fractions were divided into each components (BLM-A2, BLM B2), which had been identified by HP 1100 series LC/MSD system. All mass spectra were obtained using an HP 1100 series LC/MSD system equipped with an ionspray (pneumatically assisted electrospray) interface. Each $50 \mathrm{uL}$ of collected fractions was introduced directly into the photo-diode array detector (wave range ; $200-400 \mathrm{~nm}$ ) and subsequently into the mass spectrometer at a flow rate of $0.8 \mathrm{~mL} / \mathrm{min}$. Typically, mass scans were performed with a step size of 0.05-0.15 Da, a mass range of $500-1600 \mathrm{Da}$, gain of 3, fragmentor of $50 \sim 80 \mathrm{~V}$, which help the ions traverse the relatively high pressure region between the exit of the capillary and skimmer 1, and threshold of 50 in ESI positive mode and drying gas flow rate $\left(\mathrm{N}_{2}, \mathrm{~L} / \mathrm{min}\right.$.) of 12.5, nebulizer pressure(psig) of 50, drying gas temperature $\left({ }^{\circ} \mathrm{C}\right)$ of 340 , capillary voltage (V) of 4000 in the ionization chamber. Complete system control and data evaluation were carried out using the HP ChemStation for LC/MS. Mass tuning was performed by tuning program of HP ChemStation automatically over the entire mass range $(50-3000 \mathrm{Da})$ at positive and negative with HP tuning solution (HP ES TUNING MIX. Recorder No. G2421A). The fractions of BLM-A2 were lyophilized 
by ULVAC Lyophilyzing system (model DF-03H-S, Japan). Dried BLM-A2 was dissolved in small amount of water and lyophilized again with being divided in several vials. We obtained $11.96 \mathrm{mg}$ of BLM-A2, which was divided in 13 vials by equal amount $(0.92 \mathrm{mg})$. The quantity was measured by titration which was added by $\mathrm{Co}(\mathrm{II})$ solution and checked by the residue of unreacted BLM-A2 by using ESI-mass. The spectroscopical properties and chromatographical purity of BLM-A2 were examined by NMR (Jeol, JNM-LA series, 400MHz, Japan), mass spectroscopy and HPLC. Chromatographical purity was $95 \%$ on HPLC chromatogram. On the ${ }^{1} \mathrm{H}-\mathrm{NMR}$ spectrum and the HPLC chromatogram, there was detected some impurities which was probably resulted from degradation.

Synthesis of CoBLM-A2 Cobalt(II) chloride $94.2 \mathrm{mg}$ was dissolved in $500 \mathrm{~mL}$ of water. 0.92 mg, 1 vial, of BLM-A2 was dissolved in $5000 \mathrm{uL}$ of water and divided into 9 equal part in each reaction vials with $500 \mathrm{ul}$ respectively. Co(II) solution was added into BLM-A2 solution step by step and the added volume of $\mathrm{Co}(\mathrm{II})$ solution was $5 \mathrm{uL}$ in each step and LC/MSD was performed immediately (in 5 minutes) and when $1 \mathrm{hr}, 2 \mathrm{hr}$ elapsed after Co(II) solution was added in. The degree of complexation was monitored by NMR chemical shift change, and the final mass of each complex was identified with ESI-Mass. For structural studies, ${ }^{1} \mathrm{H}-\mathrm{NMR}$ experiments were accomplished for free- and metallo-BLM-A2 to see the conformation changes, but detail description regarding NMR based structure determination will be published elsewhere.

The distinctive peak $\left(\mathrm{m} / \mathrm{z} 708\right.$ as $\left.\left[\mathrm{BLM}-\mathrm{A} 2+\mathrm{H}^{+}\right]^{2+}\right)$ was decreased step by step and distinctive peaks of CoBLM-A2 showed up increasingly little by little. So we were able to confirm the 
completion of metallo-BLM-A2 synthesis easily through checking the amount of resided BLM-A2 with mass spectroscopy. We measured the amount of resided BLM-A2 as integrating the area of BLM-A2 on the chromatogram, which was reconstructed by the ion of $\mathrm{m} / \mathrm{z} 708$. The descent of $\mathrm{pH}$ which was due to deprotonation from the secondary amide hydrogen of the $\beta$-hydroxyhistidine moiety in metal binding site of BLM-A2 during synthesis of CoBLM-A2 $2^{13,15,16}$, took place only a little from 6 to 5 , while the complexation was made. It seems that descent of $\mathrm{pH}$ was small because the solution was very diluted.

CoBLM-A2 was formed well and fast comparatively. This method is so mild that the molecular can be detected with not losing any ligands during the analysis.

\section{RESULTS AND DISCUSSION}

The $67.12 \%$ of BLM-A2 was made immediately(within 2 or 5 minute) and $97 \%$ at $1 \mathrm{hr}$ elapsed and the reaction was made completely within 2 hrs after Co solution was added. ${ }^{13}$ Also the stability of each compounds was examined for 14 or 7 days. Each component was stable for at least 14 days under pH 5 but component 2 and 3 were unstable under $\mathrm{pH} 7$ or higher. By decreasing of component 2 and 3(2 was decreased more fast than 3), a new peak was appeared up and increased to some degrees and by more time elapsed, the peak 2, 3 and the new peak disappeared nearly completely in 7 days. 
Table 1. Suggested structures of CoBLM-A2 according to mass peaks (m/z)

\begin{tabular}{clcc}
\hline \hline \multirow{2}{*}{ Component } & \multicolumn{1}{c}{ Ion structure } & $\begin{array}{c}\mathrm{m} / \mathrm{z}, \\
\text { Measured }\end{array}$ & $\begin{array}{c}\mathrm{m} / \mathrm{z}, \\
\text { Calculated }\end{array}$ \\
\hline \multirow{2}{*}{1} & {$\left[\mathrm{Co}(\mathrm{II}) \mathrm{BLM}-\mathrm{A} 2-\mathrm{H}^{+}+\mathrm{H}^{+}\right]^{3+}$} & 491.0 & 491.1 \\
& {$\left[\mathrm{Co}(\mathrm{II}) \mathrm{BLM}-\mathrm{A} 2-\mathrm{H}^{+}\right]^{2+}$} & 736.2 & 736.2 \\
& {$\left[\mathrm{Co}(\mathrm{II}) \mathrm{BLM}-\mathrm{A} 2-\mathrm{H}^{+}+2 \mathrm{H}_{2} \mathrm{O}\right]^{2+}$} & 754.3 & 754.2 \\
& {$\left[\mathrm{Co}(\mathrm{III}) \mathrm{BLM}-\mathrm{A} 2-\mathrm{H}^{+}+\mathrm{H}_{2} \mathrm{O}+\mathrm{OH}^{-}\right]^{2+}$} & 753.8 & 753.7 \\
\hline \multirow{2}{*}{2} & {$\left[\mathrm{Co}(\mathrm{II}) \mathrm{BLM}-\mathrm{A} 2-\mathrm{H}^{+}+\mathrm{H}^{+}\right]^{3+}$} & 491.1 & 491.1 \\
& {$\left[\mathrm{Co}(\mathrm{II}) \mathrm{BLM}-\mathrm{A} 2-\mathrm{H}^{+}\right]^{2+}$} & 736.4 & 736.2 \\
& {$\left[\mathrm{Co}(\mathrm{III}) \mathrm{BLM}-\mathrm{A} 2-\mathrm{H}^{+}+\mathrm{OOH}^{-2+}\right.$} & 752.9 & 752.7 \\
& {$\left[\mathrm{Co}(\mathrm{II}) \mathrm{BLM}-\mathrm{A} 2-\mathrm{H}^{+}+\mathrm{CH}_{3} \mathrm{COOH}^{2+}\right.$} & 766.3 & 766.2 \\
\hline \hline \multirow{2}{*}{3} & {$\left[\mathrm{Co}(\mathrm{III}) \mathrm{BLM}-\mathrm{A} 2-\mathrm{H}^{+}+\mathrm{H}_{2} \mathrm{O}+\mathrm{OH}^{-}+\mathrm{H}^{+}\right]^{3+}$} & 502.9 & 502.8 \\
& {$\left[\mathrm{Co}(\mathrm{III}) \mathrm{BLM}-\mathrm{A} 2-\mathrm{H}^{+}+\mathrm{H}_{2} \mathrm{O}+\mathrm{OH}^{-}\right]^{2+}$} & 753.8 & 753.7 \\
\hline \hline
\end{tabular}

Component 1 (brown form) ${ }^{14}$ Mass spectrum which retention time was 3.03 minute on HPLC chromatogram of CoBLM-A2 gives $\mathrm{m} / \mathrm{z}$ of $491.0,736.2,754.3 . \mathrm{m} / \mathrm{z}$ of 491.0 was assigned to triply charged $\left[\mathrm{Co}(\mathrm{II}) \mathrm{BLM}-\mathrm{A} 2-\mathrm{H}^{+}+\mathrm{H}^{+}\right]^{3+}$ (calculated, 491.1). Here, $\left[-\mathrm{H}^{+}\right]$means deprotonation from the secondary amide hydrogen of the $\beta$-hydroxyhistidine moiety in metal binding site of BLM-A2 during synthesis of CoBLM-A2. ${ }^{13,15,16}$ Because BLM-A2 is basic compound with many amine functions, at LC/MSD experiment, the protonation would take place very well. So, the protonated, triply charged, [Co(II)BLM-A2 $\left.-\mathrm{H}^{+}+\mathrm{H}^{+}\right]^{3+}$ was appeared very intensively. While LC/MSD was performed in positive mode, the deprotonation could not take place nearly. So in this component 1 , the oxidation state of $\mathrm{Co}$ is $+2 . \mathrm{m} / \mathrm{z}$ of 736.2 is assigned to doubly charged [Co(II)BLM-A2 $\left.-\mathrm{H}^{+}\right]^{2+}$ (calculated, 736.2) and $\mathrm{m} / \mathrm{z}$ of 754.3 is assigned to [Co(II)BLM-A2 $\left.-\mathrm{H}^{+}+2 \mathrm{H}_{2} \mathrm{O}\right]^{2+}$ (calculated 754.2). Looking at the $\mathrm{m} / \mathrm{z} 754$ cluster more closely, a little peak of $\mathrm{m} / \mathrm{z} 753.8$ is showed in front of 
$\mathrm{m} / \mathrm{z}$ 754.3. This peak is assigned to [Co(III)BLM-A2 $\left.-\mathrm{H}^{+}+\mathrm{H}_{2} \mathrm{O}+\mathrm{OH}^{-}\right]^{2+}$ (calculated 753.7). It seems that $\left[\mathrm{Co}(\mathrm{III}) \mathrm{BLM}-\mathrm{A} 2+\mathrm{H}_{2} \mathrm{O}+\mathrm{OH}^{-}\right]$is made during mass analysis. It is strongly suggested that component 1 of CoBLM-A2 is $\mathrm{Co}(\mathrm{II})\left(2 \mathrm{H}_{2} \mathrm{O}\right)(\mathrm{BLM}-\mathrm{A} 2)$ which is formed as 6-coordinate structure composed with 4 ligands of BLM-A2 and two ligands of $2 \mathrm{H}_{2} \mathrm{O}$. [Co(II)BLM-A2 $\left.-\mathrm{H}^{+}+\mathrm{H}^{+}\right]^{3+}$ of m/z 491.0 and $\left[\mathrm{Co}(\mathrm{II}) \mathrm{BLM}-\mathrm{A} 2-\mathrm{H}^{+}\right]^{2+}$ of m/z 736.2 are the form lost $2 \mathrm{H}_{2} \mathrm{O}$ ligands from [Co(II)BLM-A2 $\left.-\mathrm{H}^{+}+2 \mathrm{H}_{2} \mathrm{O}\right]^{2+}$ during mass analysis.

Component 2 (green form) ${ }^{17}$ Mass spectrum of which retention time was 5.25 minute on HPLC chromatogram of CoBLM-A2 gives $\mathrm{m} / \mathrm{z}$ of $491.1,736.4,752.9 . \mathrm{M} / \mathrm{z}$ of 491.1 is assigned to [Co(II)BLM-A2 $\left.-\mathrm{H}^{+}+\mathrm{H}^{+}\right]^{3+}$ (calculated, 491.1), $\mathrm{m} / \mathrm{z}$ of 752.9 is assigned to [Co(III)BLM-A2 + $\left.\mathrm{OOH}^{-}-\mathrm{H}^{+}\right]^{2+}$ (calculated, 752.7) as the oxidation state of cobalt is +3 and $\mathrm{m} / \mathrm{z} 736.4$ assigned to $\left[\mathrm{Co}(\mathrm{II}) \mathrm{BLM}-\mathrm{A} 2-\mathrm{H}^{+}\right]^{2+}$ (calculated, 736.22), which oxidation state of cobalt is +2 . This could be explained as follows. $\left[\mathrm{Co}(\mathrm{III}) \mathrm{BLM}-\mathrm{A} 2+\mathrm{OOH}^{-}-\mathrm{H}^{+}\right]^{2+}$ ion lost $\mathrm{OOH}^{-}$ligand and take one electron from $\mathrm{OOH}^{-}$or others in the electronic field of ESI-mass. So Co(III) was reduced to Co(II). That is, $\left[\mathrm{Co}(\mathrm{II}) \mathrm{BLM}-\mathrm{A} 2-\mathrm{H}^{+}\right]^{2+}$ is formed during the analysis. Likewise $\left[\mathrm{Co}(\mathrm{II}) \mathrm{BLM}-\mathrm{A} 2-\mathrm{H}^{+}+\mathrm{H}^{+}\right]^{3+}$ of m/z 491.1 was made during the analysis. The peak of $\mathrm{m} / \mathrm{z} 766.3$ by which acetic acid was substituted with ${ }^{-} \mathrm{OOH}$ is appeared in mass spectrum and this peak is assigned to [Co(II)BLM-A2 $-\mathrm{H}^{+}+$ $\left.\mathrm{CH}_{3} \mathrm{COOH}\right]^{2+}$ (calculated 766.2). It is strongly suggested that component 2 of CoBLM-A2 is $\mathrm{Co}(\mathrm{III})\left(\mathrm{OOH}^{-}\right)(\mathrm{BLM}-\mathrm{A} 2)$ which is formed as 6-coordinate structure composed with 5 ligands of BLM-A2 and a ligand of $\mathrm{OOH}^{-}$as a axial ligand and the oxidation state of Cobalt ion for component 2 is +3 . 
Component 3 Mass spectrum which retention time was 12.53 minute on HPLC chromatogram of CoBLM-A2 gives $\mathrm{m} / \mathrm{z}$ of 753.8 and $\mathrm{m} / \mathrm{z}$ of $502.9 . \mathrm{m} / \mathrm{z}$ of 502.9 is assigned to [Co(III)BLM-A2 $\left.\mathrm{H}^{+}+\mathrm{H}_{2} \mathrm{O}+\mathrm{OH}^{-}+\mathrm{H}^{+}\right]^{3+}$ (calculated, 502.8) and $\mathrm{m} / \mathrm{z}$ of 753.8 is assigned to [Co(III)BLM-A2 - $\mathrm{H}^{+}+$ $\left.\mathrm{H}_{2} \mathrm{O}+\mathrm{OH}^{-}\right]^{2+}$ (calculated, 753.7). It is strongly suggested that component 3 of CoBLM-A2 is $\mathrm{Co}(\mathrm{III})\left(\mathrm{H}_{2} \mathrm{O}\right)\left(\mathrm{OH}^{-}\right)(\mathrm{BLM}-\mathrm{A} 2)$ which is formed as 6-coordinate structure composed with 4 ligands of BLM-A2, $\mathrm{H}_{2} \mathrm{O}$ and $\mathrm{OH}^{-}$as a axial ligands. The oxidation state of $\mathrm{Co}$ for component 3 is +3 . Component 3 of CoBLM-A2 is similar to component 1 in the kind of their ligands and worst of all the oxidation state of cobalt is +3 , which means that component 3 is more polar than component 1 . But the retention time is longer than component 1 , which is thought like that there might be differences of this ligand configuration. The ratio of each component is dependent on solution $\mathrm{pH}$ of reactant. It is very interesting that component 2 and 3 was made more when CoBLM-A2 was synthesized under higher $\mathrm{pH}$. Once the complex was made up, then even if the $\mathrm{pH}$ was getting lower or higher the quantity of component 2 was not changed but the quantity of component 3 was changed reversively. If the $\mathrm{pH}$ was getting lower, the quantity of compound 3 was being decreased and the $\mathrm{pH}$ higher then quantity of compound 3 increased. So we had tried to separate the mixture into each component but component 3 was made again from purely separated component 1 in solution and separated component 3 was destroyed completely. So purely separated component 1 and 3 couldn't be obtained. We strongly suggest that component 1 and 3 are coexist and they are formed as 6coordinate structure composed of 4 ligands from BLM-A2 and two ligands of $2 \mathrm{H}_{2} \mathrm{O}$ for component 1 
and $\mathrm{H}_{2} \mathrm{O}$, ${ }^{-} \mathrm{OH}$ for component 3. But the component 1 and 3 are different in their physical property. HPLC chromatogram shows that lipophilicity of 3 is bigger than that of 1 . It might be sure that the shapes of their ligands are quite different. This could be proposed as follows. In component 3 , the sulfonium ion is folded back and makes ion-pairing with $\mathrm{OH}^{-}$, so component 3 is to be more lipophilic and retained much longer than component 1 on reversed phase column of HPLC. But the retention time of component 2 is slightly bigger than that of component 1 . Out of consideration for not so much retaining of component 2 on reversed phase HPLC, the sulfonium ion might make no ion pairing with $\mathrm{OOH}^{-}$. It is proposed that $\mathrm{OOH}^{-}$might bind to $\mathrm{Co}(\mathrm{III})$ in direction at which the sugar moiety is located. The tail region containing sulfonium ion is located at the opposite side, so it couldn't make ion pairing with $\mathrm{OOH}^{-}$.
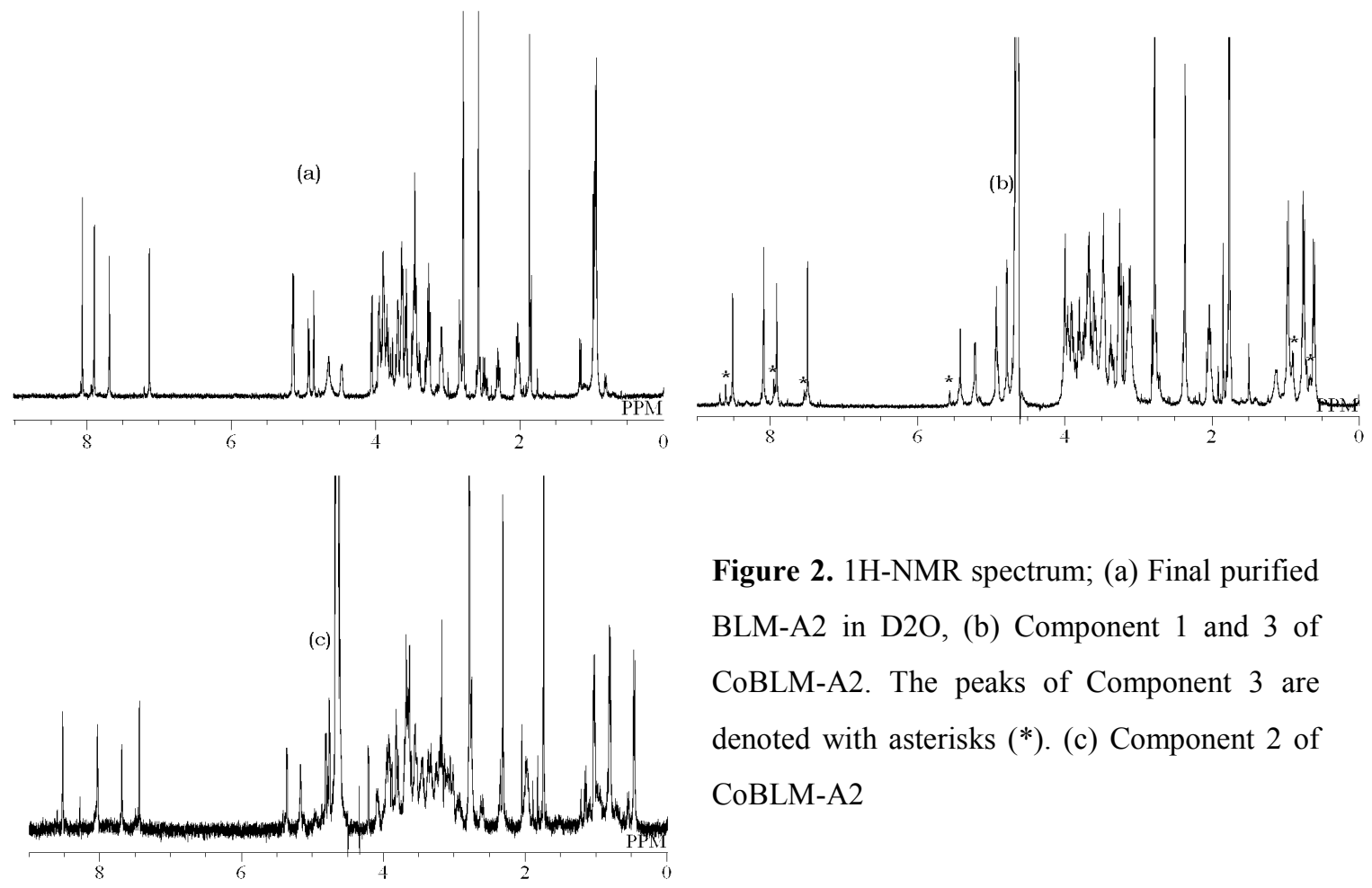

Figure 2. 1H-NMR spectrum; (a) Final purified BLM-A2 in D2O, (b) Component 1 and 3 of CoBLM-A2. The peaks of Component 3 are denoted with asterisks (*). (c) Component 2 of CoBLM-A2 
In this experiment, it was revealed newly that the brown form (component 1) was 6-coordinated structure composed with not 5 ligands but 4 ligands from BLM-A2, with $2 \mathrm{H}_{2} \mathrm{O}$ as the axial ligands and the component 3 was like as component 1 in the kind of their ligands but one of the axial ligand is $\mathrm{OH}^{-}$instead of $\mathrm{H}_{2} \mathrm{O}$. These ligands configuration is different from the green form (component 2) which is formed as 6-coordinate structure composed of 5 ligands from BLM-A2 and one ligand of $\mathrm{OOH}^{-}$, being consistent with former studies. In color of each components of CoBLM-A2, component 1 indicates reddish brown and component 2, 3 indicate green ${ }^{18,19}$, which is shown in their visible spectrum. Green color of component 2 and 3 against reddish brown color of component 1 provide strong support that the oxidation state of cobalt for component 1,2 and 3 is $+2,+3,+3$ respectively as we mentioned above.

\section{CONCLUSION}

In the synthesis of CoBLM-A2 complex, a mixture composed of two or more compounds were observed and characterized by ${ }^{1} \mathrm{H}-\mathrm{NMR}$ and mass spectrometry. We were able to separate each component with HPLC by obtaining the peaks, mainly 2 peaks (nearly equal amount on HPLC chromatogram) and one small peak, separated clearly on chromatogram (Figure 3). We found that at least 3 compounds of CoBLM-A2 were formed in the synthesis and monitored by NMR titration, and were able to identify each peak by mass spectroscopy. Stability tests were made by letting the 
Figure 3. HPLC chromatogram of CoBLM-A2 mixture synthesized by titration.

complex solutions alone at room temperature for several days and performing ESI-mass. Further structural studies will be made by NMR experiments and NMR based molecular dynamic computations. $^{20-22}$

\section{REFERENCES}

1. H. Umezawa, K. Maeda, T. Takeuchi, Y. Okami, J. Antibiot. 19A, 200 (1966).

2. H. Umezawa, Bleomycin: Current Status and New Developments, Academic Press, New York. 
15 (1978).

3. B. I. Sikic, Bleomycin Chemotherapy, Academic Press, Orlando, FL. (1985).

4. J. Stubbe, J. W. Kozarich, Chem. Rev. 87, 1107 (1987).

5. A. Natrajan, S. M. Hecht, Molecular Aspects of Anticancer Drug-DNA Interactions Vol. 2, MacMillan Press, London. 97 (1993).

6. S. A. Kane, S. M. Hecht, Prog. Nucleic Acid Res. Mol. Biol. 49, 313 (1994).

7. S. M. Hecht, Bioconjugate Chem. 5, 513 (1994).

8. S. M. Hecht, Cancer Chemotherapeutic Agents Foye, W., Ed. American Chemical Society, Washington, DC. 369 (1995).

9. J. C. Dabrowiak, Adv. Inorg. Chem. 4, 69 (1982).

10. D. H. Petering, R. W. Byrnes, W. E. Antholine, Chem. Biol. Interact. 73, 133 (1990).

11. A. H. Thomas, P. Newland, N. R. Sharma, J. Chromatogr. 337, 219 (1984).

12. R. P. Klett, J. P. Chovan, J. Chromatogr. 337, 182 (1985).

13. W. Wu, D. E. Vanderwall, S. M. Lui, X. J. Tang, C. J. Turner, J. W. Kozarich, J. Stubbe, J., J. Am. Chem. Soc. 118, 1268 (1996).

14. S. M. Lui, D. E. Vanderwall, W. Wu, X. J. Tang, C. J. Turner, J. W. Kozarich, J. Stubbe, J. J. Am. Chem. Soc. 119, 9603 (1997).

15. M. A. J. Akkerman, C. A. G. Haasnoot, C. w. Hilbers, Eur. J. Biochem. 173, 211 (1988).

16. M. A. J. Akkerman, E. W. J. F. Neijman, S. S. Wijmenga, C. W. Hilbers, W. Bermel, J. Am. Chem. Soc. 112, 7462 (1990).

17. P. Fulmer, C. Q. Zhao, W. B. Li, E. Derose, W. E. Antholine, D. H. Petering, Biochemistr 36, 4367 (1997).

18. J. Cacerescortes, H. Sugiyama, K. Ikudome, I. Saito, A. H. J. Wang, Eur J. Biochem. 244, 818 (1997).

19. Y. Iitaka, H. Nakamura, T. Nakatani, Y. Muraoka, A. Fujii, T. Takita, H. Umezawa, J. Antibiot. 31, 1070 (1978)

20. D. Kim, M. Lee, C. Lee, H. Won, H., J. Kor. Mag. Reson. 10, 163 (2006).

21. D. Kim. H. Won, J. Kor. Mag. Reson. 2, 50 (1998) 